\title{
Development of Alkylation Toluene with Methanol for Fuel on Modified ZSM-5 Zeolites by Amphoteric Surfactant
}

\author{
Akila El Morsi ${ }^{1}$, A. M. A. Omar ${ }^{1 *}$, Nora Y. Almehbad ${ }^{2}$ \\ ${ }^{1}$ Egyptian Petroleum Research Institute, Cairo, Egypt; ${ }^{2}$ Najran University, Najran, Kingdom of Saudi Arabia. \\ Email: drabdelazim123@yahoo.com, ${ }^{*}$ abdelazimomar@hotmail.com
}

Received November $11^{\text {th }}, 2013$; revised December $18^{\text {th }}, 2013$; accepted January $10^{\text {th }}, 2014$

Copyright (c) 2014 A.M.A.Omar et al. This is an open access article distributed under the Creative Commons Attribution License, which permits unrestricted use, distribution, and reproduction in any medium, provided the original work is properly cited. In accordance of the Creative Commons Attribution License all Copyrights @ 2014 are reserved for SCIRP and the owner of the intellectual property A.M.A.Omar et al. All Copyright (C) 2014 are guarded by law and by SCIRP as a guardian.

\begin{abstract}
Methylation of toluene over ZSM-5 zeolites modified by the introduction of Sr of $2.5 \%, 5 \%$, and $10 \%$ by weight was studied. Experiments were performed in a fixed bed under the conditions of reaction temperatures between $300{ }^{\circ} \mathrm{C}-500^{\circ} \mathrm{C}$, liquid hour space velocity of $4 \mathrm{~g}$ toluene/h.g catalyst, methanol to toluene ratio $4: 1$, and $0.01 \%$ of N-Octyl-N-benzyl-N-methylglycine as emulsifier. Data for conversion of toluene and selectivity towards xylene isomers showed that $2.5 \% \mathrm{Sr} / \mathrm{ZSM}-5$ catalyst has the highest conversion of toluene at $500^{\circ} \mathrm{C}$, and the lowest p-xylene selectivity, while $10 \% \mathrm{Sr} / \mathrm{ZSM}-5$ catalyst has the highest selectivity for p-xylene production. Nevertheless, the catalyst $2.5 \%$ Sr/ZSM-5 has the highest selectivity for m-xylene. The two catalysts $2.5 \%$ and $5 \%$ Sr/ZSM-5 give nearly the same selectivity for the three xylene isomers at all conversions obtained at the reaction conditions under study.
\end{abstract}

\section{KEYWORDS}

\section{Zeolite; Toluene; Methylation; Surfactances}

\section{Introduction}

Microemulsion is the stable emulsion of surfactants and co-surfactants. The wide spread interest in microemulsion and the use in industrial applications are mainly based on their high solubilization capacity for both hydrophilic and lipophilic compounds, large interfacial areas and the ultra-low interfacial tensions achieved when they coexist with excess aqueous and oil phases. The properties of micro emulsion have been extensively reviewed elsewhere $[1,2]$.

The adsorption of surfactants at interfaces plays a significant role in many physic-chemical process [3,4]. Such adsorption has been the subject of detailed studies to elucidate its mechanism and to determine the significant kinetic and thermodynamic parameters which affect it [5].

It has been shown that the performance of surfactant molecules at the interface depends strongly on the chemical structure of the molecules and on their nature [6]. Thenature of the hydrophilic group has a major effect on *Corresponding author. the effectiveness of adsorption. In general, the area per molecule at aqueous solution interfaces appears to be determined by the cross-sectional area of the hydrated hydrophilic group of the interface.

The selective preparation of para substituted for benzene derivatives by means of various modified zeolite catalysts has been reported [7-9]. In particular, ZSM-5 class zeolites have been of considerable interest because the channel dimensions are approximately the same as the molecular dimensions of many aromatic molecules.

The present work deals with the effect of added $\mathrm{N}$ octyl-N-benzyl-N-methylglyene emulsifier on the alkylation of toluene by methanol to investigate the performance of Sr/ZSM-5 catalyst of different (Sr) ratios, through the alkylation of toluene by methanol. As the product of this reaction is benzene, toluene and xylenes (BTX), which are considered as one of the most important hydrocarbon compounds on petrochemical industry. $\mathrm{N}$-octyl-N-benzyl-N-methylglyine emulsifier $\mathrm{AB}$ was synthesized elsewhere [10]. The surface tension for var- 
ious concentrations of (AB) was used by using a Kruss type 8451 Duy Noy tensiometer at different temperatures, with an accuracy of $0.20 \mathrm{mN} / \mathrm{m}$.

\section{Experimental}

Tubular flow reactor was set up for methylation of toluene with and without the addition of the emulsifier. Experimental conditions were carried out at different temperatures in the range $300^{\circ} \mathrm{C}-500^{\circ} \mathrm{C}$, and liquid hour space velocity of $4 \mathrm{~g}$ toluene/h.g. catalyst. The runs were conducted at atmospheric pressure using nitrogen gas as an eluent. Alkylation of toluene was done with methanol in the ratio of methanol to toluene of 3:1.

\section{Catalyst Preparation}

Three catalysts of ZSM-5 containing 2.5\% Sr, $5 \% \mathrm{Sr}$ and $10 \% \mathrm{Sr}$ by weight. Alumina was used as a binder for ZSM-5. These catalysts were prepared using stransium nitrate to obtain the previous catalysts of the required weight percent of stransium oxide.

\section{Results \& Discussion}

Figure 1 shows the toluene conversion versus reaction temperatures for the ZSM-5 catalyst substituted with (Sr) of the percent weight of $2.5 \%, 5 \%$, and $10 \%$ Sr. We have observed that $2.5 \mathrm{wt} \% \mathrm{Sr} / \mathrm{ZSM}-5$ catalyst gives the highest activity and 5\% S/ZSM-5 catalyst is the least one among the catalysts under study. This may happen due to elimination of the protonic acidic sites exist on the external surface of the ZSM-5 catalyst. Whereas 10\% Sr/ZSM-5 exhibits higher activity than $5 \%$ Sr/ZSM-5 catalyst, due to the decrease in the diameter of the pores of this catalyst which shifts the reaction towards selective diffusion. Figure 2 is a plot of composition of products versus temperature for $2.5 \%$ Sr/ZSM-5 catalyst. Temperature increase beyond $300^{\circ} \mathrm{C}$ has produced significant increase in para xylene to comprise $27 \%$ at $450^{\circ} \mathrm{C}$ and then slightly increase at $500^{\circ} \mathrm{C}$ to reach $30 \%$. Nevertheless $5 \% \mathrm{Sr} /$ ZSM-5 catalyst, para xylene.

Increases beyond $350^{\circ} \mathrm{C}$ to $17 \%$ at $400^{\circ} \mathrm{C}$ and then gradually increase to $25 \%$ at $500^{\circ} \mathrm{C}$ (Figure 3).

On the other hand, $10 \% \mathrm{Sr} / \mathrm{ZSM}-5$ catalyst starts to sharpen increase beyond $300^{\circ} \mathrm{C}$ to $29 \%$ paraxylene at $400^{\circ} \mathrm{C}$, then slightly increase to $30 \%$ para xylene isomer at $450^{\circ} \mathrm{C}$ (Figure 4 ).

The 2.5\% Sr/ZSM-5 and 5\% Sr/ZSM-5 catalysts, exhibit activity for the production of ethyl benzene, but the catalyst 10\% Sr/ZSM-5 does not.

The alkylation reaction of toluene by methanol proceeds in three consecuative steps according to:

$$
\begin{aligned}
& \text { Toluene }+\mathrm{MeOH} \stackrel{\mathrm{K} 1}{\longrightarrow} \mathrm{O}+\mathrm{p}-\text { xylene } \stackrel{\mathrm{K} 2}{\longrightarrow} \\
& \mathrm{O}+\mathrm{m}+\mathrm{p}-\text { xylene } \stackrel{\mathrm{K} 3}{\longrightarrow} \text { tri + tetra methyl benzene }
\end{aligned}
$$

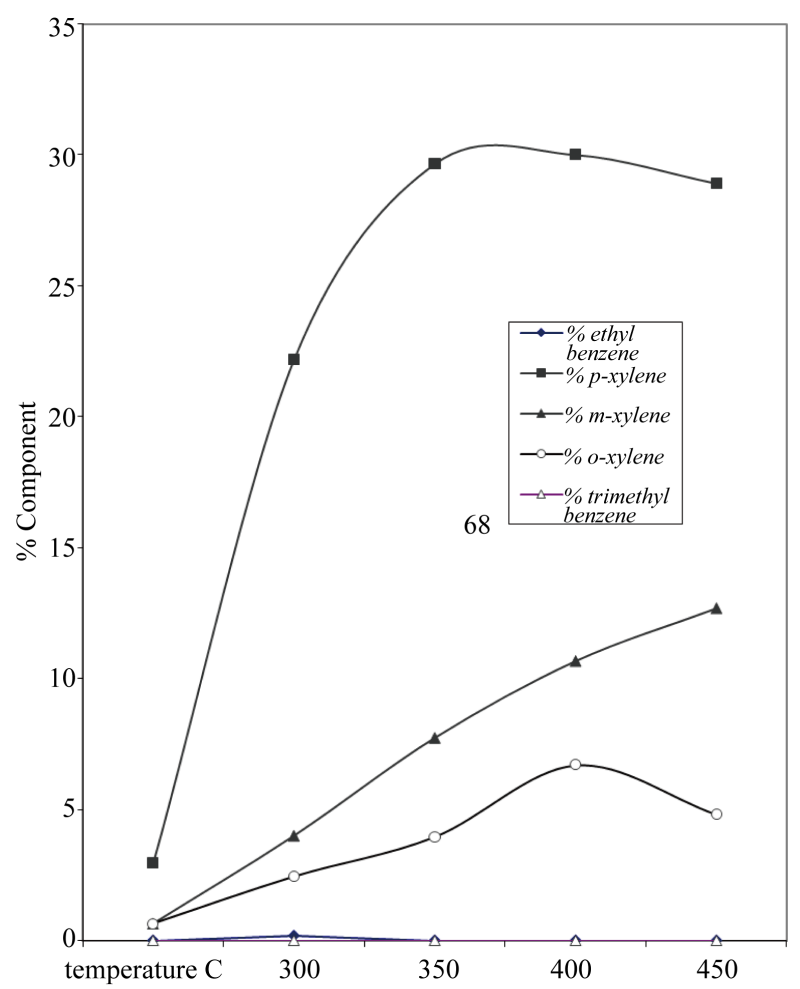

Figure 1. Effect of temperature on the product composition on $10 \% \mathrm{Sr} / \mathrm{ZSM}-5$.

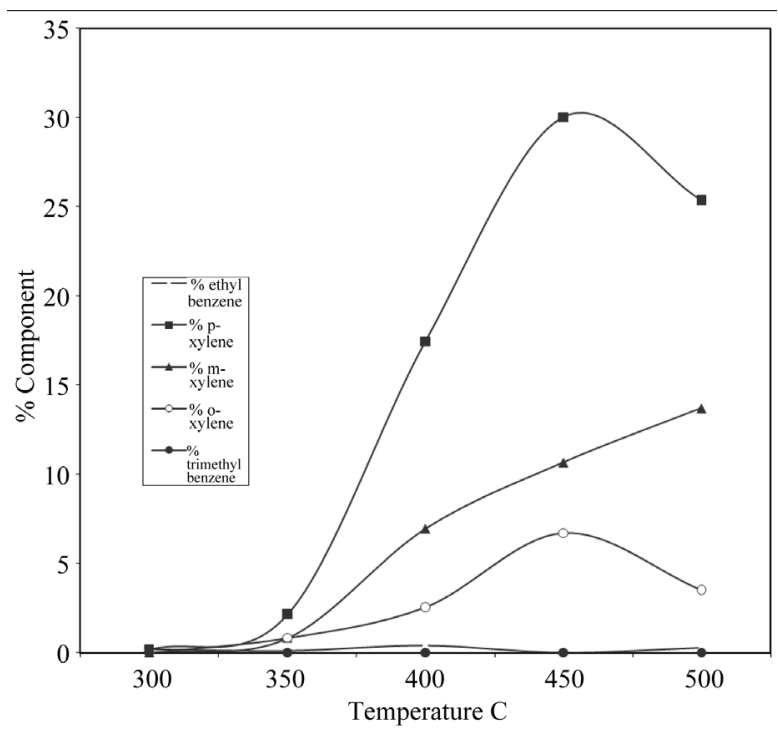

Figure 2. Effect of temperature on the product composition on $5 \%$ Sr/ZSM-5.

At high methanol concentration, it is possible that isomerization of o- and p-xylene formed in the first step proceeds with a bimolecular mechanism according to the following scheme of parallel reactions.

In this way formation of 1, 2, 4- \& 1, 2, 3- trimethylbenzene (TMB) is rationalized. In turn, m-xylene is formed by dealkylation of TMB up to equilibrium con- 

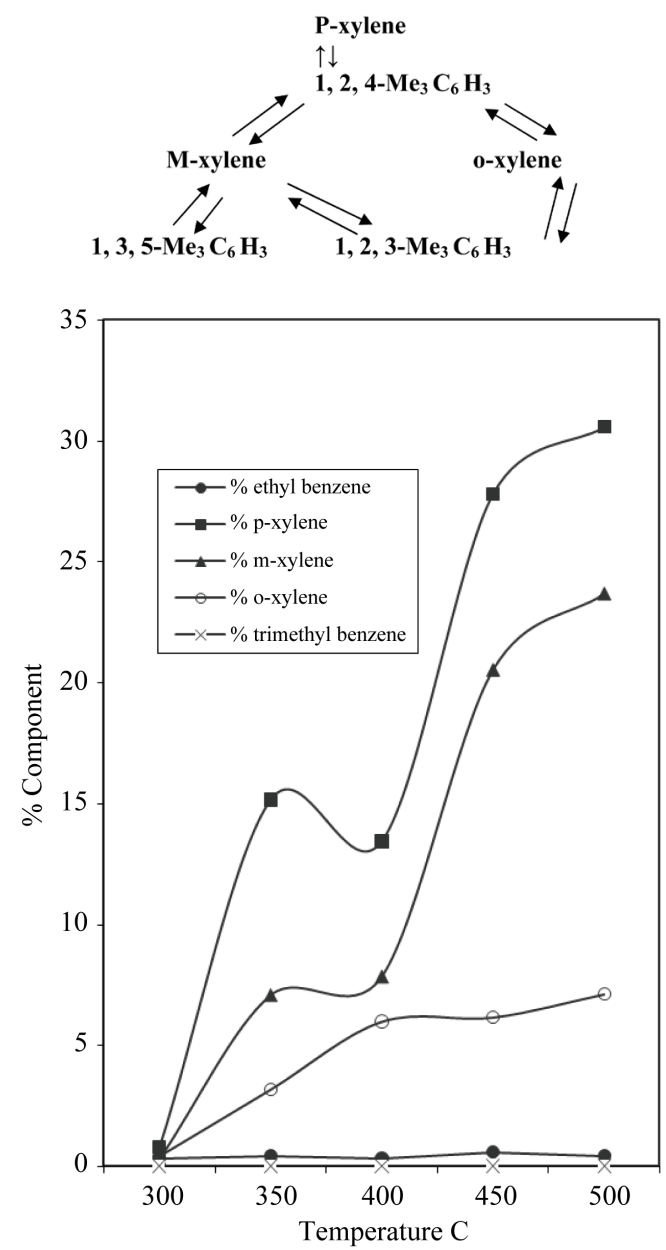

Figure 3. Effect of temperature on \% composition on $2.5 \%$ Sr/ZSM-5.

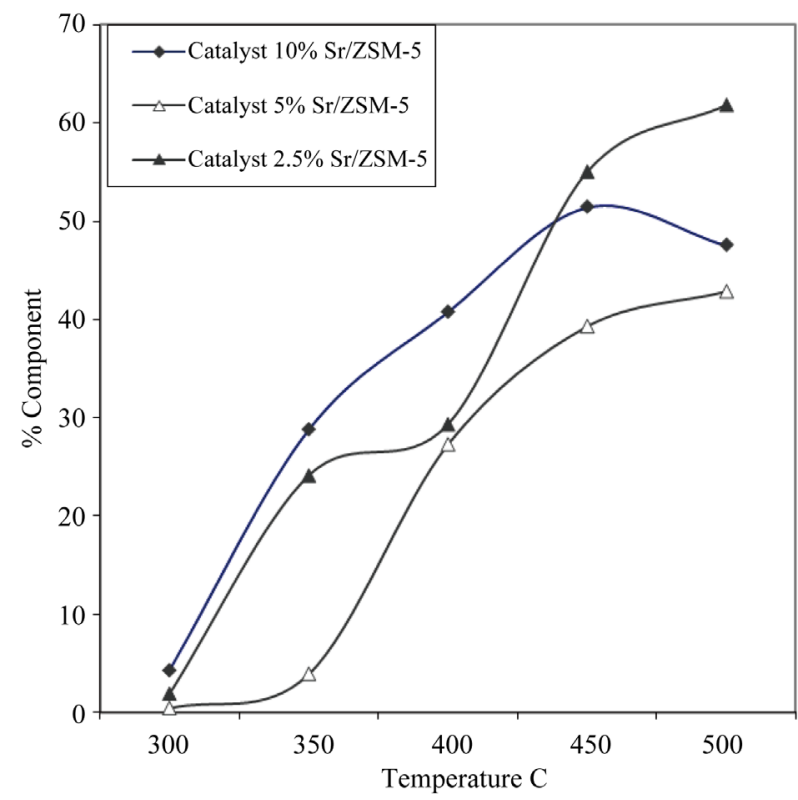

Figure 4. Effect of temperature on \% total conversion of alkylation of toluene on different catalysts. ditions.

On the two catalysts $2.5 \% \mathrm{Sr} / \mathrm{ZSM}-5$ and $5 \% \mathrm{Sr} /$ ZSM-5, (Figures 2, 3), show that the temperature influence beyond $400^{\circ} \mathrm{C}$ gives a considerable increase in m-xylene to $24 \%, 14 \%$ respectively at a reaction temperature of $500^{\circ} \mathrm{C}$. But on $10 \% \mathrm{Sr} / \mathrm{ZSM}-5$ catalyst, a linear increase in $\mathrm{m}$-xylene production is observed to reach a value of $13 \%$ at $500^{\circ} \mathrm{C}$.

Also, when comparing the Figures 2-4, it appears that using 2.5\% Sr/ZSM-5 catalyst o-xylene increases with the increase in temperature to reach a value of $6 \%$ at $400^{\circ} \mathrm{C}$ then has a constant value with futher increase in temperature. Nevertheless the catalyst 5\% Sr/ZSM-5 has a maximum value of $4 \%$ at $450^{\circ} \mathrm{C}$, while $10 \% \mathrm{SR} / \mathrm{ZSM}-5$ catalyst has a maximum value of $7.5 \%$ at $450^{\circ} \mathrm{C}$.

This can be demonstrated to that the diffusion in the micropores may not be the only reason for the high para selectivity of shape selective catalysts.

It is reasoned that ions such as $10 \% \mathrm{Sr}$ in the pores of the ZSM-5 decrease the free diameter of the catalyst and favor diffusion of sterically less requiring para isomer.

Also chemisorption of various isomers and/or toluene can play a significant role in the performance of the catalyst [11]. This takes in to account that the o-xylene is more strongly adsorbed than the Meta isomer, so different selectivity values would have been expected (Meta > ortho), Figures 2-4.

Tables 1, 2 show the conversion of toluene and the selectivity of the three catalysts understudy for producing xylenes. Also these Figures 5, 6 show that the selectivity of 5\% Sr/ZSM-5 and 2.5\% Sr/ZSM-5 catalysts for para xylene production are considerably the same till a conversion of a value $45 \%$ at which the catalyst $5 \% \mathrm{Sr} /$ ZSM-5 reaches its maximum, but the selectivity increases with further increase in conversion on the catalyst $2.5 \%$ Sr/ZSM-5.

This confirms that the reaction proceeds up to the isomerization equilibrium (step 2) of the previous equation of the alkylation reaction of toluene, and is accompanied by a rapid release of paraxylene (due to its minor adsorption) with consequently a shift in equilibrium towards formation of this isomer and enhance para selectivity. The catalyst $2.5 \% \mathrm{Sr} / \mathrm{ZSM}-5$ has the highest selectivity towards m-xylene at all temperatures under study.

The selectivity plot for o-xylene production (Table 1) is lower than the corresponding for metaxylene values. The maximum value for production of metaxylene was obtained at $500^{\circ} \mathrm{C}$ on the catalyst $2.5 \% \mathrm{Sr} / \mathrm{ZSM}-5$.

The results presented in Table 1 revealed that the selectivity for the production of the three xylene isomers may be due to the close relation between the acidity of the exchanged zeolites and the selective adsorption of the xylene isomers. The para isomer is adsorbed less than the other for more acidic zeolite ZSM-5. 
Table 1. Reaction products for alkylation of toluene at different temperatures.

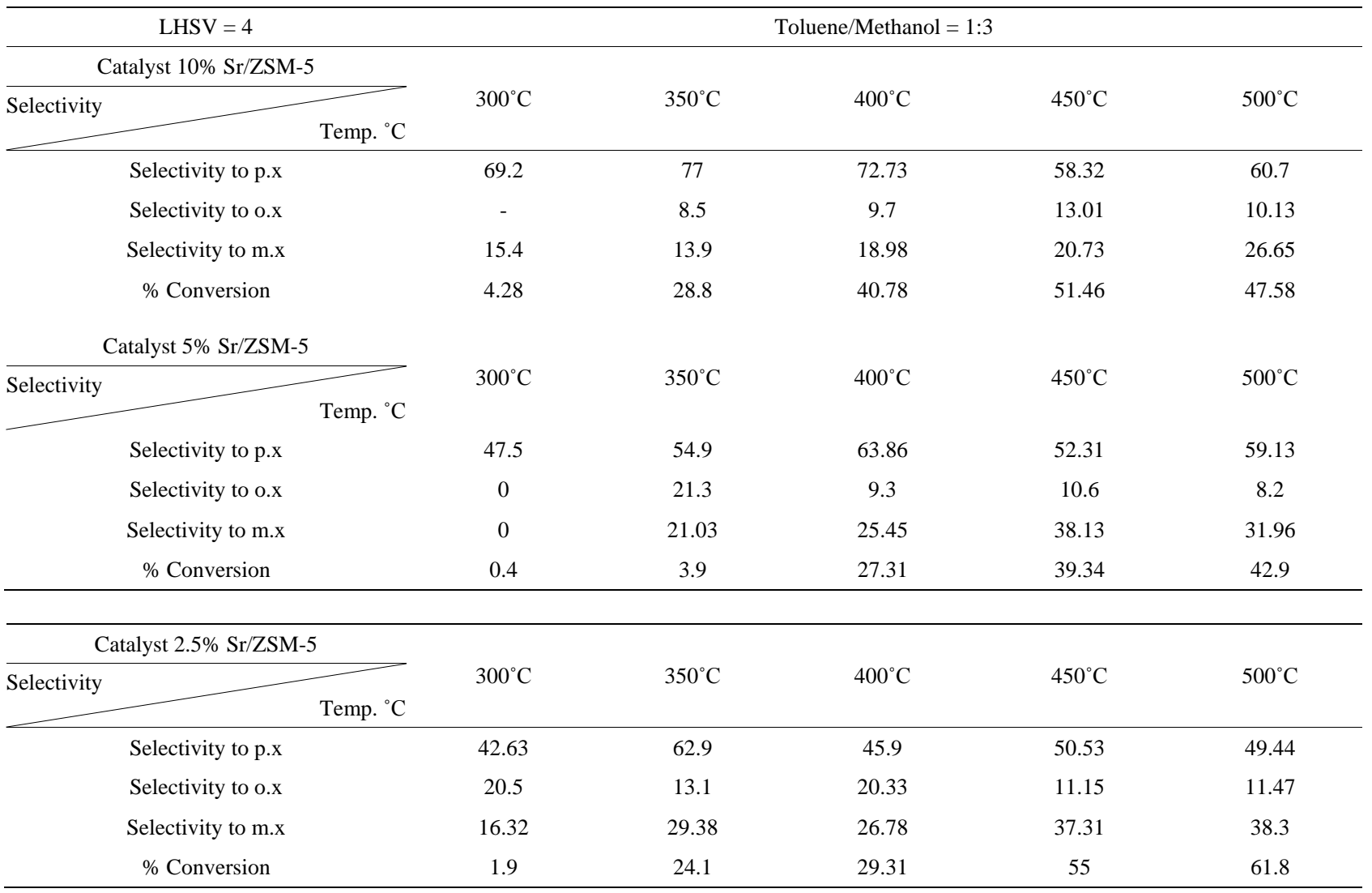

Table 2. Reaction products for alkylation of toluene at different temperatures and catalysts.

\begin{tabular}{cccccc}
\hline \multirow{2}{*}{ Type of catalysts } & \multicolumn{5}{c}{ \% Total conversion after modification by the additive AB at different temperatures } \\
\cline { 2 - 6 } & 300C & 350C & 400C & 450C & 500C \\
\hline Sr/ZSM-5 10\% & 5.9 & 32.8 & 44.7 & 61.5 & 62.9 \\
Sr/ZSM-5 5\% & 0.6 & 4.5 & 33 & 48.6 & 52 \\
Sr/ZSM-2.5\% 5 & 0.4 & 8.5 & 10 & 25.52 & 30.1 \\
\hline
\end{tabular}

The applications of (AB) as emulsifier are based on its capacity for adsorption at various interfaces with consequent alteration of the properties of surface. The most fundamental effect of adsorption of (AB) is the reduction of interfacial tension which, in the case of equilibriumreversible adsorption, is described by the Gibbs equation.

A series of experiments was conducted at 25C employing a mixing time of $15 \mathrm{~min}$. And a stirring rate of $1200 \mathrm{rpm}$. The results obtained are depicted in Figure 5 in terms of the emulsion stability, interfacial tension between toluene/methanol versus the molar concentration of AB employed. Emulsion stability was improved as the concentration of $\mathrm{AB}$ increased with a maximum being attained at $5 \mathrm{~mol} / \mathrm{l}$. At the same time, the interfacial tension between toluene/methanol phase decreased from 31 $\mathrm{mN} / \mathrm{m}$ to $18 \mathrm{mN} / \mathrm{m}$. Such results demonstrate that an increase in the $\mathrm{AB}$ concentration was accompanied by its increase in emulsion stability.

The explanation for these results is that those molecules of $\mathrm{AB}$ that are highly effective at reducing the critical micelle concentration and interfacial tension between toluene/water, toluene is solubilized in the micelle core. The additive $A B$ have more than one group capable of forming hydrogen bond, with methanol in a terminal polar grouping appear to produce greater dispersion and emulsion stability.

It can be suggested that the adsorption layer of surfactant with its hydrophilic end oriented towards aqueous layer agree with author publication early [12]. This emulsion toluene/methanol stablized by the additive AB. The sign of the charge on the dispersed droplets is amphipathic ion. The presence of the additive in interfacial film 
between toluene/methanol close approach two phases droplets to each other which can be enhance degree of alkylation.

At the optimum conditions $10 \% \mathrm{Sr} / \mathrm{ZSM}-5$, LHSV equals 4 , toluene/methanol ratio of $1: 3$ and temperature $450 \mathrm{C}$. The alkylation of toluene with methanol was carried out. Enhancing of the concentration of the product was achieved. Detailed analysis of the products is given in Table 3.

It is clear that the yield of alkylation increase and selectivity towards p-xylene and o-xylene also incease. These results can be explained according to micelle formation and interfacial tension. Reaction occurring at the methanol/toluene interface strongly facilitating reaction by micelles catalyzed reaction and does not depend on its concentration.

Table 3. Reaction products for alkylation of toluene at different temperatures.

\begin{tabular}{|c|c|c|c|c|c|}
\hline LHSV $=4$ & \multicolumn{5}{|c|}{ Toluene/Methanol = 1:3 } \\
\hline \multicolumn{6}{|c|}{ Catalyst $10 \%$ Sr/ZSM-5 } \\
\hline \% component & $300^{\circ} \mathrm{C}$ & $350^{\circ} \mathrm{C}$ & $400^{\circ} \mathrm{C}$ & $450^{\circ} \mathrm{C}$ & $500^{\circ} \mathrm{C}$ \\
\hline \multicolumn{6}{|c|}{ Temp. ${ }^{\circ} \mathrm{C}$} \\
\hline Toluene & 95.75 & 71.13 & 59.22 & 48.54 & 52.42 \\
\hline Ethyl benzene & - & 0.18 & - & - & - \\
\hline p.x & 2.96 & 22.18 & 29.66 & 30.01 & 28.92 \\
\hline $\operatorname{m.x}$ & 0.66 & 4.01 & 7.74 & 10.67 & 12.68 \\
\hline $0 . x$ & 0.65 & 2.45 & 3.96 & 6.70 & 4.82 \\
\hline TMP & - & - & - & - & - \\
\hline$\%$ conversion & 4.28 & 28.8 & 40.78 & 51.46 & 47.58 \\
\hline \multicolumn{6}{|c|}{ Catalyst 5\% Sr/ZSM-5 } \\
\hline \% component & $300^{\circ} \mathrm{C}$ & $350^{\circ} \mathrm{C}$ & $400^{\circ} \mathrm{C}$ & $450^{\circ} \mathrm{C}$ & $500^{\circ} \mathrm{C}$ \\
\hline \multicolumn{6}{|c|}{ Temp. ${ }^{\circ} \mathrm{C}$} \\
\hline Toluene & 99.62 & 96.12 & 72.69 & 48.54 & 57.15 \\
\hline Ethyl benzene & 0.19 & 0.10 & 0.39 & - & 0.27 \\
\hline p.x & 0.19 & 2.14 & 17.44 & 30.01 & 25.37 \\
\hline $\mathrm{m} \cdot \mathrm{x}$ & 0 & 0.82 & 6.95 & 10.67 & 13.71 \\
\hline $0 . \mathrm{x}$ & 0 & 0.83 & 2.55 & 6.70 & 3.52 \\
\hline TMP & - & - & - & - & - \\
\hline$\%$ conversion & 0.4 & 3.9 & 27.31 & 39.34 & 42.9 \\
\hline \multicolumn{6}{|c|}{ Catalyst 2.5\% Sr/ZSM-5 } \\
\hline \% component & $300^{\circ} \mathrm{C}$ & $350^{\circ} \mathrm{C}$ & $400^{\circ} \mathrm{C}$ & $450^{\circ} \mathrm{C}$ & $500^{\circ} \mathrm{C}$ \\
\hline \multicolumn{6}{|c|}{ Temp. ${ }^{\circ} \mathrm{C}$} \\
\hline Toluene & 98.12 & 75.93 & 70.69 & 45 & 38.25 \\
\hline Ethyl benzene & 0.35 & 0.42 & 0.33 & 0.57 & 0.43 \\
\hline p.x & 0.81 & 15.16 & 13.44 & 27.79 & 30.56 \\
\hline $\operatorname{m.x}$ & 0.31 & 7.08 & 7.85 & 20.52 & 23.67 \\
\hline $0 . x$ & 0.39 & 3.15 & 5.96 & 6.13 & 7.09 \\
\hline TMP & - & - & - & - & - \\
\hline$\%$ conversion & 1.9 & 24.1 & 29.31 & 55 & 61.8 \\
\hline
\end{tabular}




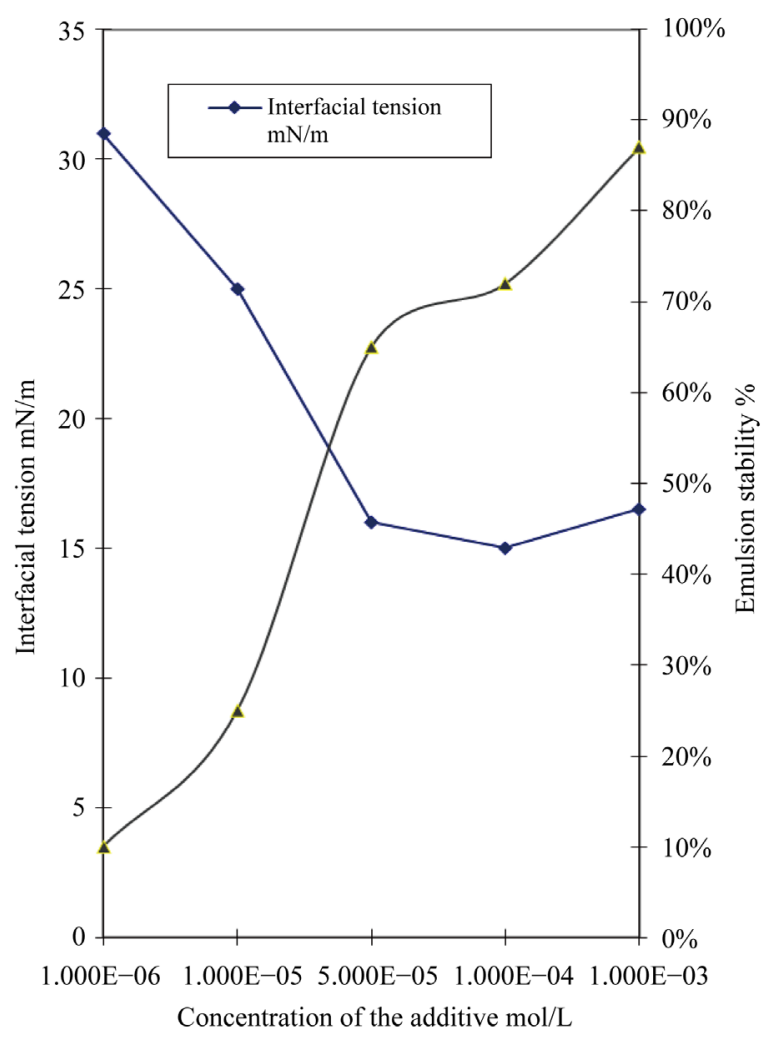

Figure 5. Effect of concentration of the additive on interfacial tension of toluene/methanol and emulsion stability.

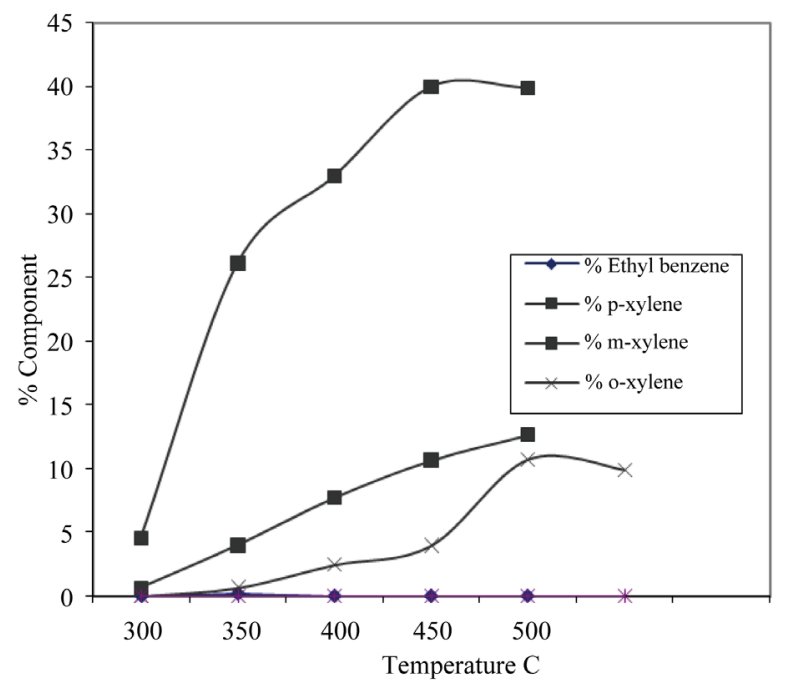

Figure 6. Effect of temperature on the product composition on the modified $10 \%$ Sr/ZSM-5.

\section{Conclusion}

The yield of alkylation of toluene and its selectivity towards $\mathrm{p}$-xylene and o-xylene increase by $\mathrm{N}$-octyl-Nbenzyl-N-methylglyene. These results are discussed according to micelle formation and interfacial tension. Reaction occurring at the methanol/toluene interface strongly facilitating reaction by micelles catalyzed reaction does not depend on its concentration

\section{REFERENCES}

[1] Th. F. Tadros, "In Surfactant in Solution,” Plenun Press, New York, 1984, pp. 1501-1532

[2] D. O. Shah, "Macro- and Micro-Emulsion, Theory and Applications,” American Chemical Society, Washington DC, 1985.

[3] J. Drelich, A. Atia, M. Yalamanchil and J. D. Miller, "Formation and Wetting Characteristics of Adsorbed Layers of Unsaturated Carboxylic Acids at a Fluorite Surface,” Journal of Colloid and Interface Science, Vol. 178, No. 2, 1996, pp. 720-732. http://dx.doi.org/10.1006/jcis.1996.0170

[4] J. A. Mielczarskin and C. Mielczarski, "Determination of Molecular Orientation and Thickness of Self-Assembled Monolayers of Oleate on Apatite by FTIR Reflection Spectroscopy," The Journal of Physical Chemistry, Vol. 99, No. 10, 1995, pp. 3206-3217. http://dx.doi.org/10.1021/j100010a035

[5] P. Somasundaran, "Separation and Purification Methods," Vol. 1, Marcel Dekker, New York, 1972, p.117.

[6] P. M. Holland and D. N. Rubingh, "Mixed Surfactant System," American Chemical Society, Washington DC, 1992. http://dx.doi.org/10.1021/bk-1992-0501

[7] J. L. Sotelo, M. A. Vguina, J. L. Valverde and D. P. Serano, "Kinetics of Toluene Alkylation with Methanol over Magnesium-Modified ZSM-5,” Industrial \& Engineering Chemistry Research, Vol. 32, No. 11, 1993, 2548-2554. http://dx.doi.org/10.1021/ie00023a018

[8] M. Guisnet and P. Magnoux, "Coking and Deactivation of Zeolites: Influence of the Pore Structure,” Applied Catalysis, Vol. 54, No. 1, 1989, pp. 1-27. http://dx.doi.org/10.1016/S0166-9834(00)82350-7

[9] D. M. Bibby, R. F. Dowe and G. M. Mcleellan, "Coke Formation in High-Silica Zeolites,” Applied Catalysis A: General, Vol. 93, No. 1, 1992, pp. 1-34. http://dx.doi.org/10.1016/0926-860X(92)80291-J

[10] A. M. A. Omar, "Separation of Emulsifiable Oil from a Flotation Solution by Surface Tension Control," Adsorption science \& Technology, Vol. 19, No. 1, 2001, pp. 91100. http://dx.doi.org/10.1260/0263617011494006.

[11] S. G. T. Bhat, "Selectivity for Xylene Isomers in the Reaction of Alkylation of Toluene with Methanol on Zeolite Catalysts,” Journal of Catalysis, Vol. 75, No. 1, 1982, pp. 196-199. http://dx.doi.org/10.1016/0021-9517(82)90136-1

[12] S. M. Csicsery, "Acid Catalyzed Isomerization of Dialkylbenzenes,” The Journal of Organic Chemistry, Vol. 34, No. 11, 1969, pp. 3338-3342. http://dx.doi.org/10.1021/jo01263a026 